\title{
Characteristics of toxicity and haemorrhagic toxin produced by Clostridium sporogenes in various animals and cultured cells
}

\author{
Y. HARA-KUDO, A. OGURA*, Y. NOGUCHI* and S. KUMAGAI \\ Department of Biomedical Food Research and *Veterinary Science, National Institute of Health, 1-23-1 \\ Toyama, Shinjuku-ku, Tokyo 162, Japan
}

\begin{abstract}
The toxic effects of the haemorrhagic toxin of Clostridium sporogenes were studied in mice, rats, guinea-pigs and rabbits, and in various cultured cells. In rabbits, but not in the other animals, intradermal injection with crude toxin and its injection into a ligated intestinal loop caused haemorrhage in both the skin and intestinal wall. Intraperitoneal (i.p.) injection of crude toxin similarly caused death only of rabbits, with marked haemorrhage in the serous surface of kidney, intestines, liver, spleen, mesentery and diaphragm. Histological examination of the rabbits killed after i.p. inoculation revealed leakage of blood into a space beneath the serous membranes of parenchymatous organs in the peritoneal cavity and within the loose connective tissues in the mesentery and diaphragm. Cytotoxicity of partially purified haemorrhagic toxin in vitro was noted with rabbit aorta endothelial cells, human skin capillary vein endothelial cells and bovine pulmonary artery endothelial cells, but not with Chinese hamster ovary cells, Vero cells, human epitheloid carcinoma cells, human colon carcinoma cells (T84) and human colon adenocarcinoma cells (Caco 2). The results suggest that the haemorrhagic toxin of $C$. sporogenes exerts its effects in rabbits but not in mice, rats or guinea-pigs, through direct action on endothelial cells.
\end{abstract}

\section{Introduction}

Clostridia such as Clostridium difficile, C. sordellii, $C$. spiroforme and $C$. perfringens have been implicated as causative agents of spontaneous or antibioticassociated enterotoxaemia and diarrhoea in various species of animals including man [1]. In recent years, it has been shown that $C$. sporogenes is frequently associated with diarrhoea in cefmetazole (cephems antibiotic)-treated rabbits [2]. The culture medium of C. sporogenes isolated from the caecal contents of the antibiotic-treated rabbits induced fluid secretion in rabbit ileal loops [2]. Histological study revealed marked haemorrhage in the mucosa and oedema with haemorrhage in the submucosa of the affected loops [2]. When injected subcutaneously in the back of rabbits, the culture medium induced haemorrhagic patches at the injected sites [2]. These findings indicated that the isolates of $C$. sporogenes produced a haemorrhagic enterotoxin.

Received 25 June 1996; revised version accepted 29 Aug. 1996.

Corresponding author: Dr Y. Hara-Kudo.
To further characterise the biological action of the toxin, the toxic effects of culture filtrates of C. sporogenes isolated from cefmetazole-treated diarrhoeic rabbits on mice, rats, guinea-pigs and rabbits and on various cultured cells were studied.

\section{Materials and methods}

Preparation of crude and partially purified toxins of $C$. sporogenes

A C. sporogenes isolate from cefmetazole-associated diarrhoeic rabbits was incubated in $10 \mathrm{~L}$ of Trypticase Soy Broth (BBL, Becton Dickinson, Cockeyville, MD, USA) for $15 \mathrm{~h}$ at $37^{\circ} \mathrm{C}$. After separation from the bacterial cells by centrifugation at $7000 \mathrm{~g}$ for $30 \mathrm{~min}$ at $4^{\circ} \mathrm{C}$, the culture supernate was concentrated to $1 / 10$ volume by ultrafiltration with stirred cells and a YM membrane (Amicon, Danvers, MA, USA). Ammonium sulphate was then added to the culture supernate to give $80 \%$ saturation, and the precipitate was collected by centrifugation at $10000 \mathrm{~g}$ for $30 \mathrm{~min}$ at $4^{\circ} \mathrm{C}$. The precipitate was dissolved in $50 \mathrm{~mm}$ Tris- $\mathrm{HCl}$ buffer $(\mathrm{pH}$ 7.5) and then dialysed against 80 volumes of the same buffer with three changes. A portion of the dialysate, 
crude toxin, was stored at $-80^{\circ} \mathrm{C}$ pending tests in vivo. The remainder was concentrated further to $1 / 5$ volume by ultrafiltration as described above, and then applied to a column of Sephacryl S-300 HR $(2.5 \times 120 \mathrm{~cm}$, Pharmacia, Uppsala, Sweden), followed by elution with $50 \mathrm{~mm}$ Tris-HCl buffer ( $\mathrm{pH} 7.5$ ) containing $0.2 \mathrm{M}$ $\mathrm{NaCl}$. Fractions $(4 \mathrm{ml})$ were collected, and those with haemorrhagic activity in rabbit skin were combined, concentrated to $1 / 22$ volume by ultrafiltration with stirred cells and a YM membrane and then dialysed against $50 \mathrm{~mm}$ phosphate buffer $(\mathrm{pH} \mathrm{6.8)}$ to be used as partially purified toxin in cytotoxicity tests. The titre of haemorrhagic toxin was expressed as haemorrhagic units (HU); haemorrhage was measured by a rabbit skin reaction at $18 \mathrm{~h}$ after intradermal (i.d.) injection of $100 \mu 1$ of the toxin preparation and the minimum dose that produced a haemorrhagic spot in the skin of $10 \mathrm{~mm}$ diameter was defined as $1 \mathrm{HU}$ [3].

\section{Animals}

Eleven female Japanese white rabbits, $1.5 \mathrm{~kg}$ in weight (Funabashi Farm, Funabashi, Japan), 10 male Hartley guinea-pigs, $250 \mathrm{~g}$ in weight (SLC, Int., Hamamatsu, Japan), 10 6-week-old male Wistar rats (SLC) and 16 male 6-week-old BALB/c mice (SLC), were used for tests in vivo. The crude toxin was injected into the animals intradermally, intravenously (i.v.), intraperitoneally (i.p.) or into ligated loops made in the small intestine. I.d. injection was into the shaved back of the animals, and i.v. injection was through the ear vein of rabbits or femoral vein of guinea-pigs, rats and mice. Preparation of the ligated loops and injection of the crude toxin into them were performed through an abdominal incision made under pentobarbital (Dainippon Pharmaceutical Co. Ltd, Osaka, Japan) anaesthesia. The loops were made in the mid-jejunum. Haemorrhagic patches in the back skin, if any, were measured $18 \mathrm{~h}$ after i.d. injection. The animals given the toxin into the intestinal loops were killed for examination of fluid accumulation in the loops $5 \mathrm{~h}$ after the treatment, and the i.v.- and i.p.-treated animals were killed 48 and 6-24 h, respectively, after the treatment, by excess anaesthesia with pentobarbital for the rabbits and ether for the other animals.

\section{Pathological examinations}

The liver, heart, lung, kidneys, intestines, spleen, diaphragm and mesentery were removed after gross pathological examination. The specimens were fixed in buffered formalin, dehydrated in a graded alcohol series, and embedded in paraffin. Sections 3-5 $\mu \mathrm{m}$ thick were stained with haematoxylin and eosin $(\mathrm{H} \&$ E).

\section{Cytotoxicity tests with cultured cells}

Rabbit aorta endothelial cells (RAE) were isolated aseptically from female Japanese white rabbits by established techniques [4] and grown in Medium 199 (M199, Nissui Pharmaceutical Co., Tokyo, Japan) with glutamine (Nissui Pharmaceutical Co.) $0.5 \%, 5 \mathrm{mM} \mathrm{N}$ 22-hydroxyethylpiperazine- $N^{\prime}$-2-ethanesulphonic acid (HEPES, Dojindo, Kumamoto Prefecture, Japan), penicillin-streptomycin (100 IU/ml-100 $\mu \mathrm{g} / \mathrm{ml}$, Dainippon Pharmaceutical Co. Ltd) and supplemented with inactivated fetal bovine serum $20 \%$. Human skin capillary vein endothelial cells (MvE) purchased from Dainippon Pharmaceutical Co. Ltd were grown in MvE Medium $^{\mathrm{TM}}$ (Dainippon Pharmaceutical Co. Ltd) supplemented with human recombinant EGF and FGF (Gibco BRL Co., Grand Island, NY, USA). Bovine pulmonary artery endothelial cells (CPAE), Chinese hamster ovary cells (CHO-Kl) and Vero cells purchased from Japanese Cancer Resources Bank (JCRB, Tokyo, Japan) were grown in modified Eagle's medium (MEM, Nissui Pharmaceutical Co.) supplemented with inactivated fetal bovine serum $20 \%, 10 \%$ and $5 \%$, respectively. Human epitheloid carcinoma cells (HeLa S-3) purchased from JCRB were grown in Ham's F12 medium (Nissui Pharmaceutical Co.). Human colon carcinoma cells ( $\mathrm{T}$ 84, CCL248) purchased from the American Type Culture Collection (ATCC, MD, USA) were grown in a 1:1 mixture of Dulbecco's modified Eagle's medium (DMEM, Nissui Pharmaceutical Co.) and Ham's F12 medium with $15 \mathrm{mM}$ HEPES, glutamine, non-essential amino acid (Gibco BRL), penicillin-streptomycin $(100 \mathrm{IU} / \mathrm{ml}-100 \mu \mathrm{g} / \mathrm{ml})$ and supplemented with inactivated fetal bovine serum $10 \%$. Human colon adenocarcinoma cells (Caco 2, HTB37) purchased from ATCC were grown in DMEM medium with glutamine, non-essential amino acid, penicillinstreptomycin $(100 \mathrm{IU} / \mathrm{ml}-100 \mu \mathrm{g} / \mathrm{ml})$ and supplemented with inactivated fetal bovine serum $10 \%$. Incubation for cell growth was performed in a $\mathrm{CO}_{2} \quad 5 \%$ atmosphere at $37^{\circ} \mathrm{C}$. Freshly trypsinised cells were inoculated in 96-well plates (Corning, NY, USA) with $10^{4}$ cells/well and pre-incubated for $2 \mathrm{~h}$ in $\mathrm{CO}_{2} 5 \%$ at $37^{\circ} \mathrm{C}$. The partially purified toxin was added to the cells, followed by incubation for $48 \mathrm{~h}$ in $\mathrm{CO}_{2} 5 \%$ at $37^{\circ} \mathrm{C}$. After incubation, viable cells were stained with crystal violet by changing the medium with crystal violet $0.4 \%$ solution. Absorbance of ethanol extracts of the cells at $550 \mathrm{~nm}$ was measured with a spectrophotometer (Model 2550 microplate reader, BioRad, CA, USA) [5]. Viability of the cells was expressed as the percentage of viable cells in the presence of the toxin to those in its absence.

\section{Results}

Toxicity of $C$. sporogenes haemorrhagic toxin in mice, rats, guinea-pigs and rabbits

I.d. injection of crude toxin induced a clear haemorrhagic reaction at the injection site of rabbits. However, haemorrhage, oedema and congestion are not observed in other animals even when four-fold higher concentrations of the crude toxin were injected i.d. (Table 1). 
Table 1. Effect of crude haemorrhagic toxin of $C$. sporogenes on animals

\begin{tabular}{|c|c|c|c|c|c|c|c|c|c|c|c|c|}
\hline \multirow[b]{2}{*}{ Animals } & \multicolumn{3}{|c|}{ Intradermal injection } & \multicolumn{3}{|c|}{ Intravenous injection } & \multicolumn{3}{|c|}{ Intraperitoneal injection } & \multicolumn{3}{|c|}{ Intestinal loop test } \\
\hline & Effect & $\begin{array}{c}\text { Dose } \\
\text { (HU/0.1 ml) }\end{array}$ & $\mathrm{n}$ & Effect & $\begin{array}{c}\text { Dose } \\
(\mathrm{HU} / \mathrm{kg})\end{array}$ & $\mathrm{n}$ & Effect & $\begin{array}{c}\text { Dose } \\
\text { (HU/kg) }\end{array}$ & $\mathrm{n}$ & Effect & $\begin{array}{c}\text { Dose } \\
(\mathrm{HU} / \mathrm{ml})\end{array}$ & $\mathrm{n}$ \\
\hline Mice & - & 4 & 4 & - & 2000 & 4 & - & 4000 & 4 & - & $40 / 0.1$ & 4 \\
\hline Rats & - & 4 & 2 & - & 1066 & 2 & - & 2666 & 2 & - & $43 / 0.2$ & 4 \\
\hline Guinea-pigs & - & 4 & 2 & - & 2080 & 2 & - & 4800 & 2 & - & $44 / 0.5$ & 4 \\
\hline Rabbits & + & 1 & 3 & - & 533 & 2 & + & 2400 & 4 & + & $270 / 2.0$ & 2 \\
\hline
\end{tabular}

Haemorrhagic unit $(1 \mathrm{HU}$ : haemorrhagic reaction of $10 \mathrm{~mm}$ in diameter) of the crude toxin was determined by the rabbit skin test. $\mathrm{n}$, Number of animals tested.

Intradermal injection: + , haemorrhage $(>1 \mathrm{HU})$; - , no change. Intravenous injection: - , not lethal. Intraperitoneal injection: + , lethal effect; - , no change. Intestinal loop test: + , haemorrhage; - , no change.

I.v. injection of the crude toxin at a dose $>500 \mathrm{HU} / \mathrm{kg}$ body weight caused no pathological changes in any of the animals (Table 1). I.p. injection ( $2400 \mathrm{HU} / \mathrm{kg}$ ) caused severe damage in rabbits, but even higher doses caused neither gross lesions nor any other observable symptoms in the other animals. Two rabbits died within $24 \mathrm{~h}$ and the other two were killed 6 and $24 \mathrm{~h}$ after toxin treatment.

After treatment with the haemorrhagic toxin produced by $C$. sporogenes, only rabbits showed noticeable pathological changes. The autopsy of all rabbits of the i.p. group revealed an accumulation of blood-containing fluid in peritoneal and, to a lesser extent, pleural cavities. Haemorrhage of varying shapes and sizes was observed in serosal membranes of caecum, small intestine, abdominal wall, mesentery and diaphragm. Histological examination of the rabbit killed $6 \mathrm{~h}$ after i.p. injection of toxin revealed a leakage of blood into the space beneath serous membrane. In the parenchymatous organs such as kidney, intestine, liver and spleen, bleeding was confined to the outermost areas (Fig. 1A). In the diaphragm and mesentery, free blood cells were found within loose connective tissues among adipose tissue (Fig. 1B) or among muscular bundles (Fig. 1C). The organs in the thoraxic cavity (heart, lung and thymus) showed no histological abnormalities. After i.d. injection of the toxin, macroscopic haemorrhage (c. $10 \mathrm{~mm}$ in diameter) could be observed around the injection site in the skin. Microscopically, there was a heavy haemorrhage associated with leucocyte infiltration in the intestinal connective tissue of the epidermal and dermal layers (data not shown).

\section{Toxicity of $C$. sporogenes haemorrhagic toxin in cultured endothelial cells}

As shown in Fig. 2, 11 fractions (fractions 76-86) from a Sephacryl S-300 HR column exhibited haemorrhagic reactions in rabbit skin, and these fractions were combined, concentrated and then used as partially purified toxin for cytotoxicity tests.

The viability of RAE, MvE and CPAE was reduced by the partially purified toxin at concentrations of $0.08-60 \mathrm{HU} / \mathrm{ml}(0.013-9.6 \mu \mathrm{g}$ of protein) in a concentration-dependent manner (Fig. 3). When these cultured cells were incubated with the toxin (24$60 \mathrm{HU} / \mathrm{ml}$ ) for $48 \mathrm{~h}$, the toxin inhibited growth. Under phase-contrast microscopy, the toxin caused rounding of the cells and detachment from the culture plate. However, the toxin did not affect the viability of CHO-K1, Vero, T84, Caco2 and HeLa S-3, at concentrations of $42.3,42.3,10,10$ and $2.5 \mathrm{HU} / \mathrm{ml}$ respectively.

\section{Discussion}

Rabbits displayed severe trauma upon receiving either the crude toxin of $C$. sporogenes by i.d. or i.p. injection or injection into ligated jejunal loop. No obvious toxic effects were noted in the other species investigated, even though they received HU doses higher than those given to rabbits. This indicates that the rabbit is extremely sensitive to the toxin of $C$. sporogenes compared with rat, mouse and guinea-pig. Whether the ineffectiveness of i.v.-injected toxin in the animals except for rabbits was because a lower dose was required to elicit toxicity or due to efficient clearance of the toxin from the blood circulation by other species remains uncertain.

Characteristic features of the gross and microscopic lesions in the rabbits receiving i.p. injection with crude toxin were severe haemorrhage in serosal surfaces of the organs in the peritoneal cavity, mesentery and diaphragm. In-vitro tests with cultured cells showed apparent cytotoxicity of the partially purified haemorrhagic toxin to endothelial cells, but not to the other cells, suggesting that vascular endothelial cells are the primary target of this toxin. Thus the toxin may cause the increase of permeability or destruction of blood capillary wall, or both, through direct action on the endothelial cells, although the possible involvement of some mediators in the haemorrhagic process cannot be excluded. Haemorrhage was restricted to the outermost areas of the parenchymatous organs, indicating that the toxin 

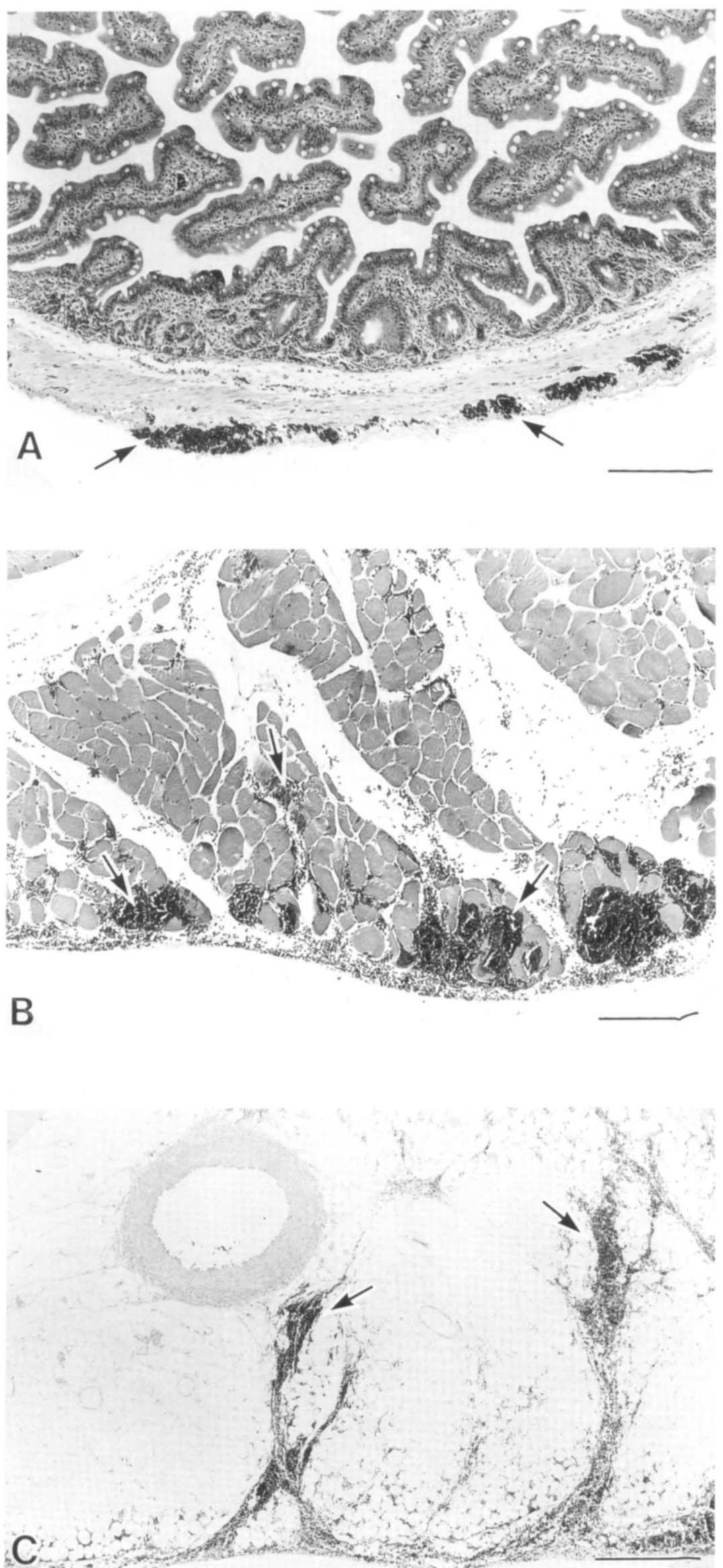

Fig. 1. Light microscopy of tissue from a rabbit inoculated i.p. with $C$. sporogenes culture supernate. A, jejunum: haemorrhage is evident beneath the serous membrane (arrows); neither inflammation nor necrosis can be observed. Bar $=500 \mu \mathrm{m}$. B, diaphragm: free blood cells can be seen in loose connective tissue among muscular bundles (arrows). $\mathrm{Bar}=500 \mu \mathrm{m}$. C, mesentery: haemorrhage is evident between the lobes of adipose tissue (arrows). Bar $=1 \mathrm{~mm}$. 


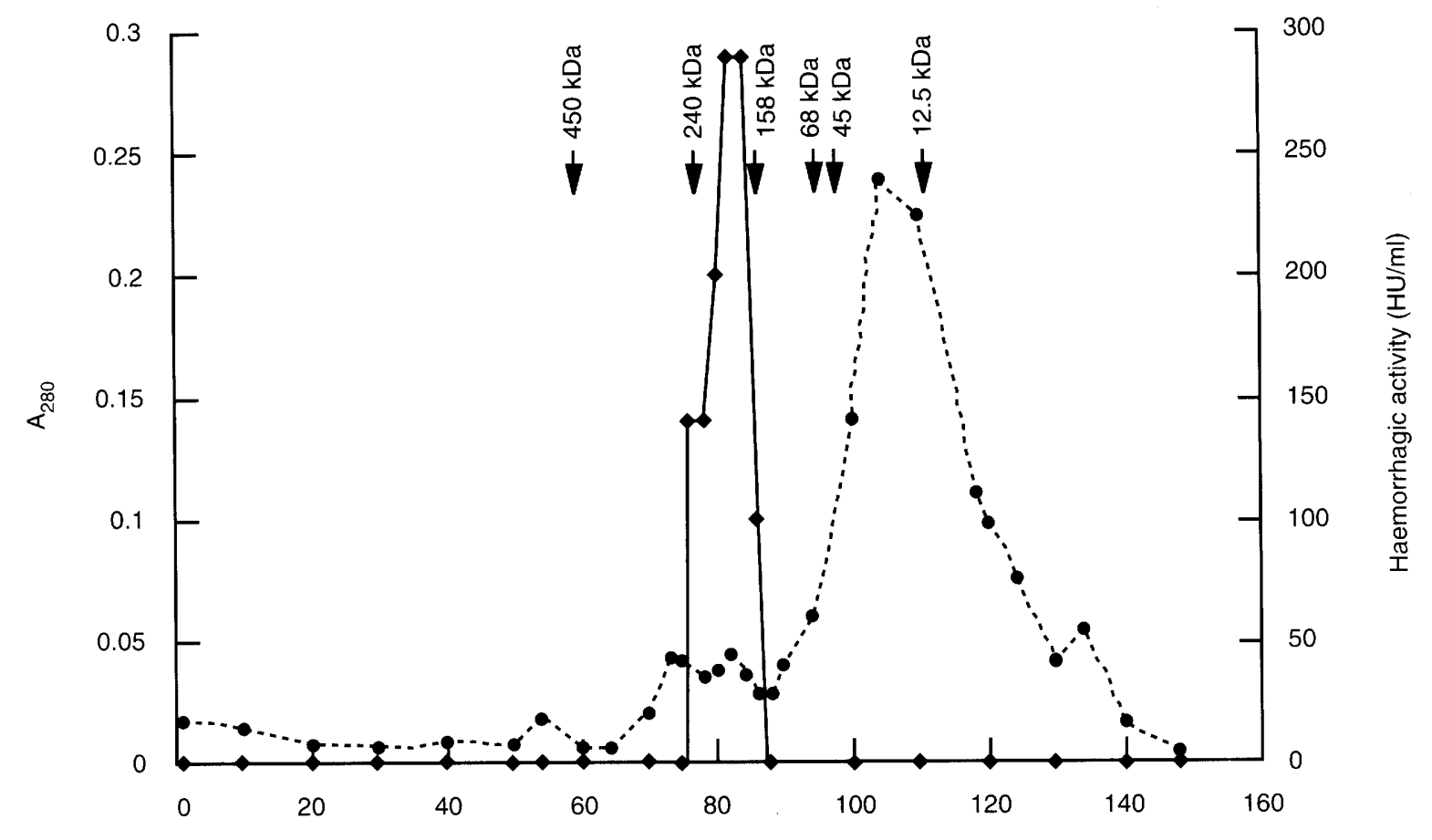

Fraction no.

Fig. 2. Sephacryl S-300 HR chromatography of haemorrhagic toxin produced by $C$. sporogenes. Concentrated culture supernate of $C$. sporogenes was applied to the Sephacryl column and eluted with $50 \mathrm{~mm}$ Tris- $\mathrm{HCl}$ buffer (pH 7.5 ) containing $0.2 \mathrm{M} \mathrm{NaCl} ; 4-\mathrm{ml}$ fractions were collected and their haemorrhagic activity was examined by the rabbit skin test. - - - , $\mathrm{A}_{280} ; \longrightarrow$, haemorrhagic activity $(\mathrm{HV} / \mathrm{ml})$.

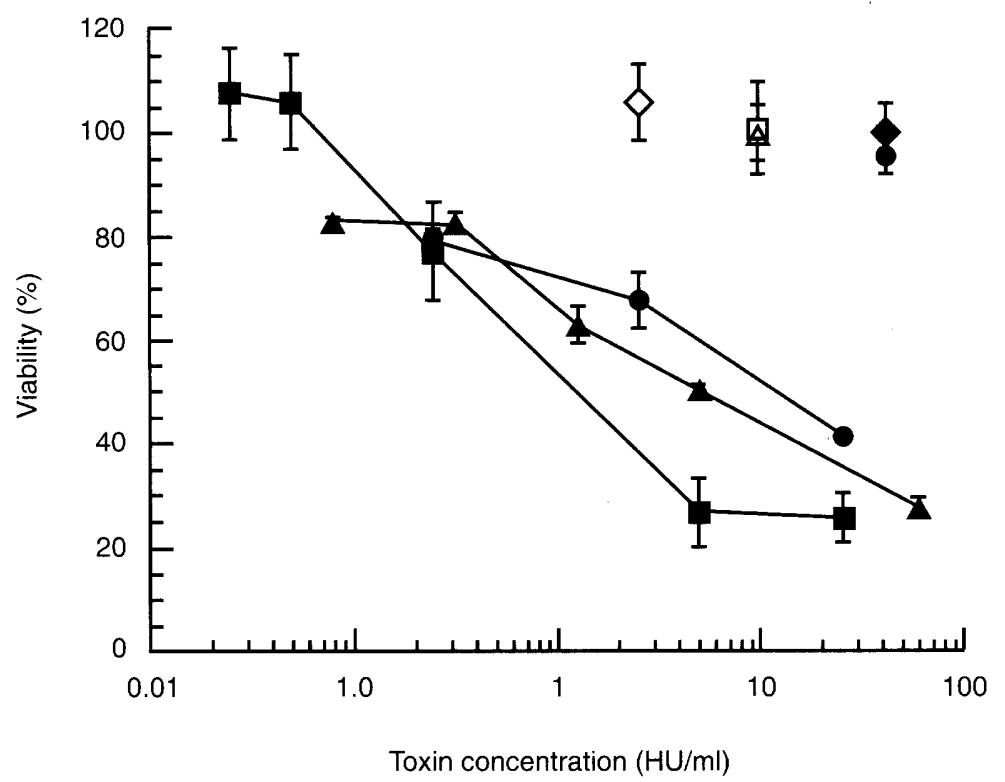

Fig. 3. Cytotoxicity of the partially purified toxin. Viability was expressed as a percentage of viable cells in the presence of the toxin to those in its absence. Each point and vertical bar indicate the mean and SEM of triplicate determinations. - RAE; $\boldsymbol{\square}, \mathrm{MvE} ; \boldsymbol{\Delta}, \mathrm{CPAE} ; \bullet, \mathrm{CHO}-\mathrm{K} 1 ; \mathrm{O}$, Vero; $\square$, T84; $\triangle$, Caco $2 ; \diamond$, Hela S-3.

cannot easily penetrate into the organ across serosal membranes or into the blood circulation across the capillary wall.

The effects of crude toxin in rabbits are similar in several aspects to the toxic effects of toxin A of C. difficile and haemorrhagic toxin (HT) of C. sordellii on laboratory animals. These toxins have been found to induce haemorrhage in the small intestine when injected into a ligated intestinal loop [6-8] and in cutaneous tissues when injected i.d. $[6,9,10]$. Haemorrhage in mesentery and diaphragm has been observed in rats receiving i.p. injection of HT of C. sordellii [7]. However, the effect of haemorrhagic toxin of $C$. 
sporogenes is different from the other two toxins in susceptible species; rat, mouse and guinea-pig were resistant to the toxin of $C$. sporogenes, whereas they have been observed to be susceptible to the toxins of C. difficile and $C$. sordellii [10-12]. Furthermore, in contrast to severe trauma in rabbits receiving i.p. injection with the toxin of $C$. sporogenes, no obvious signs were observed in the animals that died that received i.p. or i.d. injection with toxin $\mathrm{A}$ of $C$. difficile [13]. The exposure of intestinal mucosa to toxin A of C. difficile produced an injury to villus tips at the early stage of intestinal damage [14]. A previous study showed that the cultured supernate of C. sporogenes, when injected into the intestinal loops, induced mucosal and submucosal haemorrhage without any damage to epithelial cells [2]. Thus, the haemorrhagic toxin of $C$. sporogenes is distinct from the other clostridial toxins that have haemorrhagic activity from the point of view of biological activity. Physicochemical and immunological studies on this toxin are now in progress.

\section{References}

1. Hatheway CL. Toxigenic clostridia. Clin Microbiol Rev 1990; 3: $66-98$.

2. Hara $\mathrm{Y}$, Igimi S, Kasuga $\mathrm{F}$ et al. Isolation of enterotoxinproducing Clostridium sporogenes from cefmetazole-associated diarrheic rabbit. J Vet Med Sci 1991; 53: 531-532.

3. Kondo H, Kondo S, Sadahiro S, Yamaguchi K, Ohsaka A,
Murata R. Standardization of antivenine. II A method for determination of antihemorrhagic potency of $\mathrm{Habu}$ antivenine in the presence of two hemorrhagic principles and their antibodies. Jpn J Med Sci Biol 1965; 18: 127-141.

4. Rone JD, Goodman AL. Heterogeneity of rabbit aortic endothelial cells in primary culture. Proc Soc Exp Biol Med 1987; 184: 495-503

5. Saotome K, Morita H, Umeda M. Cytotoxicity test with simplified crystal violet staining method using microtitre plates and its application to injection drugs. Toxic in Vitro 1989; 3: 317-321.

6. Lyerly DM, Lockwood DE, Richardson SH, Wilkins TD. Biological activities of toxins $\mathrm{A}$ and $\mathrm{B}$ of Clostridium difficile. Infect Immun 1982; 35: 1147-1150.

7. Lima AAM, Lyerly DM, Wilkins TD, Innes DJ, Guerrant RL. Effects of Clostridium difficile toxins $\mathrm{A}$ and $\mathrm{B}$ in rabbit small and large intestine in vivo and on culture cells in vitro. Infect Immun 1988; 56: 582-588.

8. Martinez R, Wilkins TD. Purification and characterization of Clostridium sordellii hemorrhagic toxin and cross-reactivity with Clostridium difficile toxin A (enterotoxin). Infect Immun 1988; 56: 1215-1221.

9. Ryden EB, Lipman NS, Taylor NS, Rose R, Fox JG. Clostridium difficile typhlitis associated with cecal mucosal hyperplasia in Syrian hamster. Lab Animal Sci 1991; 41: $553-558$.

10. Arseculeratne SN, Panabokké RG, Wijesundera S. The toxins responsible for the lesions of Clostridium sordellii gas gangrene. J Med Microbiol 1969; 2: 37-53.

11. Taylor NS, Thorne GM, Bartlett JG. Comparison of two toxins produced by Clostridium difficile. Infect Immun 1981; 34: 1036-1043.

12. Lyerly DM, Saum KE, MacDonald DK, Wilkins TD. Effects of Clostridium difficile toxins given intragastrically to animals. Infect Immun 1985; 47: 349--352.

13. Lyerly DM, Krivan HC, Wilkins TD. Clostridium difficile: its disease and toxins. Clin Microbiol Rev 1988; 1: 1-18.

14. Stephen J, Redmond SC, Mitchell TJ et al. Clostridium difficile enterotoxin (toxin A): new results. Biochem Soc Trans 1984; 12: $194-195$. 